\title{
The Bethesda system for reporting thyroid cytopathology: Should Sri Lanka adopt it?
}

\author{
Professor. Chandu de Silva \\ Chair and Senior Professor of Pathology \\ Department of Pathology, Faculty of Medicine, University of Colombo
}

\begin{abstract}
:
Fine needle aspiration (FNA) is a frontline investigation in the management of solitary thyroid nodules. It reduces unnecessary surgery in patients with benign nodules and helps to triage patients with malignant nodules for surgery. If FNA is to be clinically useful, the cytopathology report has to be unambiguous and should guide the referring physician to appropriate therapy. It is also essential for endocrinologists, physicians and surgeons to be familiar with the reporting format and terminology used. This article will describe the Bethesda system for reporting thyroid cytopathology (BSRTC), compare it with the existing system used in Sri Lanka and discuss why it should adopted in this country.
\end{abstract}

\section{INTRODUCTION:}

A solitary nodule in the thyroid could be a colloid cyst, a dominant hyperplastic nodule in a multinodular goiter, a follicular adenoma or carcinoma or any other type of thyroid malignancy. As some studies have claimed a sensitivity and specificity of over $90 \%$, FNA is recommended as the initial step in the evaluation of solitary thyroid nodules ( $I, 2)$. FNA helps to identify patients with a benign cytology pattern who need follow up and triage patients with likely thyroid neoplasms for early surgery.According to some studies FNA can have a $92 \%$ negative predictive value for a benign diagnosis and up to a $100 \%$ positive predictive value for a malignant diagnosis (3). Despite thyroid cytology being widely used as a first-line investigation to guide clinical management, until recently, there was no standardized terminology for FNA reporting (4). Currently different systems are being used for thyroid cytopathology reporting. Clinicians should work closely with the cytopathologist and be familiar with the local reporting format and terminology used for FNA reporting of the thyroid. They should also be aware of potential diagnostic pitfalls that may lead to false positive results to avoid unnecessary surgery (2). Current Sri Lankan guidelines recommend the THY I-5 system which is adopted from the British
Thyroid Association FNAC reporting guidelines (5). This article will discuss the usefulness of the Bethesda system for reporting thyroid cytopathology (6) and why it may be more useful than the currently used THY I-5 system.

\section{THE BETHESDA SYSTEM FOR REPORTING THYROID CYTOPATHOLOGY (BSRTC)}

In October 2007, "The National Cancer Institute $(\mathrm{NCl})$, Thyroid Fine Needle Aspiration State of the Science Conference" was held in Bethesda, Maryland hosted by the $\mathrm{NCl}$ with the intention of formulating internationally acceptable guidelines for reporting of thyroid cytopathology. This was because there was much confusion regarding terminology used by different laboratories and countries. The discussions and conclusions regarding terminology and morphologic criteria were summarized in publications by Baloch at al $(7,8)$ and formed the framework for the publication of the book on BSRTC (6). The Bethesda system recommends that each thyroid FNA report begin with a general diagnostic category. There are six diagnostic categories in the BSRTC (Table I). Each diagnostic category carries an implied cancer risk ranging from $0-3 \%$ for the "benign category" to nearly 100\% for the "malignant category" (Table 2). The Bethesda system differs from the Thy system (Table 3 ) in that each category is linked to evidence based clinical management guidelines. Thus clinicians aware of these guidelines will find it easier to interpret FNA reports in terms of further management.

\section{BSRTC CATEGORY I: NON-DIAGNOSTICI UNSATISFACTORY (ND/UNS)}

This category is similar in both BSRTC and THY systems. Smears which contain less than six groups of well visualized (i.e., well-stained, undistorted and unobscured) follicular cells with at least ten cells per group are included in this category. Poor cellular yield could be due to a sampling error when the needle is not in the lesion, faulty aspiration technique or due 
to inherent pathology of the lesion such as in fibrous variant of Hashimoto thyroiditis, Riedel thyroiditis, vascular neoplasms, long standing cysts or lesions with thick fibrous capsules (9).

Smears containing cyst fluid only with cyst macrophages and without abundant colloid are included in the ND/UNS category. This is to avoid false negative diagnosis of a cystic papillary carcinoma. Thus such cases are reported as ND/UNS followed by the sub-category "cyst fluid only".The THY system also adopt similar terminology. Clinicians should be aware of this and take note especially if the cysts are complex and over $3 \mathrm{~cm}$ in diameter.

Adequacy should be judged in a clinical context, with correlation of ultrasound findings. Presence of abundant easily recognizable colloid in an ultrasonically cystic lesion without suspicious solid areas could be diagnosed as a benign smear compatible with a colloid cyst even if there are few or no follicular epithelial cells $(6,10)$. Smears in patients with lymphocytic (Hashimoto) thyroiditis, thyroid abscess or granulomatous thyroiditis may contain less than six clusters of follicular cells but are categorized as benign based on the abundance of inflammatory cells (6). Any smear with less than six clusters of follicular cells but with atypia even in a single cluster should be categorized as atypia of undetermined significance (AUS) or suspicious for malignancy depending on the cytological features (6).

Solid nodules with an initial ND/UNS result should be re-aspirated, but only after about three months. This is to avoid false positive results due to reactive or reparative changes (II). On site evaluation of ultrasound guided FNA of solid nodules can improve diagnostic interpretation in up to $60 \%$ of the cases (I2). Most nodules with ND/UNS prove to be benign (13). As the risk of malignancy in pure cystic lesions is low, it may not be necessary to re-aspirate ultrasonically, benign, cystic nodules with an initial ND/UNS result (6).

\section{BSRTC CATEGORY 2: BENIGN}

This is the most common category in thyroid cytopathology. Smears with abundant colloid, cyst macrophages and more than six wellvisualized normal-looking follicular epithelial cells can be categorized as benign. The follicular cells in this category are arranged predominately in monolayered, evenly spaced (honeycomb-like) sheets or clusters. This category will include pathological entities such as colloid nodules, nodules in Graves' disease, hyperplastic nodules and macrofollicular type follicular adenomas. Inflammatory smears indicating lymphocytic or granulomatous thyroiditis are included in this category. Potential diagnostic pitfalls include presence of abundant colloid in a welldifferentiated follicular carcinoma (9) and presence of large numbers of cyst macrophages and degenerated follicular epithelial cells in a cystic papillary carcinoma (14). It is important to note that cellularity alone is not sufficient to include smears in the follicular neoplasm or suspicious for follicular neoplasm (FN/ SFN) category (BSRTC category 4). Follicular cell crowding, overlapping and microfollicular formation affecting a majority of follicular cells are important to diagnose FN/SFN category (15). Although this categorization is done by cytopathologists, clinicians should be aware of this potential pitfall especially if the cytopathology report is FN/SFN, when the lesion is ultrasonically and clinically benign (6). The presence of a few Hurthle cells also does not warrant a diagnosis of Hurthle cell neoplasm/ suspicious for Hurthle cell neoplasm.A minor population of Hurthle cells is a common finding in benign follicular nodules (BFN) (6).

It is not possible to distinguish between a nodular goiter (NG) and a colloid rich macrofollicular adenoma by cytology. Thus the latter will be diagnosed cytologically as a BFN. The decision for surgery will depend on clinical features, ultrasonic appearance and size of the nodule.

Lymphocytic (Hashimoto) thyroiditis is included under the benign category. A predominance of either the lymphoid or the Hurthle cell population may raise the possibility of a lymphoma or a Hurthle cell neoplasm respectively $(16,17)$. A prominent monomorphic lymphoid population may require additional samples for flow cytometry (6) or require histological assessment if flow cytometry is not available. It is also important for clinicians to be aware that a false positive diagnosis of papillary carcinoma can be made if the Hurthle cells in a smear with lymphocytic thyroiditis exhibit nuclear enlargement, grooves and chromatin clearing. The diagnostic threshold for papillary carcinoma should be raised in a smear showing background features of lymphocytic thyroiditis. If features are equivocal the smear can be categorized as suspicious for malignancy (Bethesda category 5). 
The BSRTC category 2 and the THY category 2 are similar with usage of similar diagnostic criteria. The management for this category is clinical follow up with physical examination supplemented by ultrasonography in some cases (18). Follow up can be carried out at 6- 18 month intervals and for at least 3-5 years following the initial benign diagnosis (6). Repeat FNA is recommended for nodules showing significant growth or displaying ultrasonic abnormalities such as irregular margins, microcalcifications, intra-nodular vascularity and hypoechogenecity in solid areas (6, II). The risk for malignancy in this category is difficult to calculate as most patients do not have surgery. Most published studies publish a false negative rate in the range of $1-10 \%(19,20,21)$. However all these included only surgically resected nodules in the calculation and therefore suffered from selection bias. Surgery for BSRTC category 2 is recommended only for large, symptomatic or clinically/sonographically worrisome nodules or if associated with a contralateral malignancy (6).

\section{BSRTC CATEGORY 3:ATYPIA OF UNDETERMINED SIGNIFICANCE/FOLLICULAR LESION OF UNDETERMINED SIGNIFICANCE (AUS/FLUS)}

The classification of "indeterminate" lesions that are not clearly benign or malignant have been confusing for cytopathologists and clinicians. There is variation in how cytopathologists interpret and report such smears. Clinicians have tended to lump reports such as "follicular lesion", "follicular proliferation", "atypical", "follicular neoplasm", "indeterminate for malignancy" and "suspicious for malignancy" into a single "indeterminate for malignant category" for conceptual or even management purposes (6). Category 3 is the major category that differs from the THY system. The biggest advantage of the BSRTC system is that the criteria for categories 3,4 and 5 are well defined and have been linked to evidence based management guidelines as opposed to the THY category 3.

The AUS/FLUS category is reserved for smears that contain follicular, lymphoid or other cells with architectural and/or nuclear atypia that is not sufficient to be classified as suspicious for follicular neoplasm or suspicious for malignancy (BSRTC categories 4 and 5). This category includes smears with microfollicles that are insufficient in number for a diagnosis of follicular neoplasm or when a predominance of microfollicles are seen in a sparsely cellular smear. It is also used when there is a predominance of Hurtle cells in a sparsely cellular aspirate with scant colloid, when focal nuclear features of papillary carcinoma are present in a smear with an otherwise predominant benign follicular cell population, when atypical cyst lining cells are present in an otherwise benign sample and when a minor population of follicular cells show nuclear enlargement and prominent nucleoli.

AUS results have been reported in $3-18 \%$ of thyroid FNAs (6). Despite clear definitions this category has only fair reproducibility among pathologists. As a provisional goal for most practice settings the proportion of BSRTC category 3 should be about $7 \%$ of all thyroid FNAs (6). This is a category of last resort and should not be used indiscriminately. The major difference between THY category 3 (possible neoplasm) and BSRTC category 3 is that the former includes a heterogenic group ranging from hyperplastic nodules to thyroid adenomas and carcinomas, whilst in the BSRTC system follicular adenomas and carcinoams are included in category 4.

The recommended management for BSRTC category 2 is based on clinical correlation and most cases will require a repeat FNA after an appropriate interval (22). A repeat FNA usually results in a more definitive diagnosis and only about $20-25 \%$ of nodules repeatedly fall into this category $(22,23)$. The risk for malignancy in this category is difficult to determine as only a sub-set of patients will have surgery. The risk of malignancy is probably in the range of $5-15 \%$ (6).

\section{BSRTC CATEGORY 4: FOLLICULAR NEOPLASM OR SUSPICIOUS FOR FOLLICULAR NEOPLASM (FN/SFN)}

In the past thyroid aspirations that are suspicious for a thyroid neoplasm have been reported as "follicular lesion", "follicular proliferation", "indeterminate" "suspicious for follicular neoplasm" etc causing much confusion among clinicians. It is true that nodular hyperplasia,follicular adenoma and follicular carcinoma have overlapping cytomorphological features which make distinction between them difficult. In fact in the THY system they are mostly included under THY 3 category. Nevertheless certain features are suggestive of a neoplasm and especially raise the possibility of a follicular carcinoma. These features include, moderately or markedly cellular smears with cell crowding, microfollicles, and dispersed isolated cells. Some nuclear atypia may be seen with enlarged variably sized nuclei and prominent nucleoli. Colloid is 
scant or absent. Such smears are categorized as BSRTC category 4 (6). Often microfollicles are misdiagnosed. A small fragment of follicular cells is not necessarily a microfollicle. Crowding and overlapping of cells are important defining features of a microfollicle (6). It is important to be aware that follicular adenomas and hyperplastic nodules may demonstrate nuclear enlargement and hyperchromasia (25). Cytology of an aspirate of the parathyroid gland may mimic a follicular neoplasm.

A nodule with a diagnosis of BSRTC category 4 has a $65-85 \%$ likelihood of being neoplastic (6). The rate of malignancy is about $12-32 \%$ (6). About $27-68 \%$ of such malignancies are interpreted histologically as papillary thyroid carcinoma $(6,22,26,27)$.

The recommended management for a patient with a diagnosis of FN/ SFN (BSRTC category 4) is surgical excision of the lesion, most often a hemithyroidectomy or lobectomy (6).

\section{BSRTC CATEGORY 5: SUSPICIOUS FOR MALIGNANCY (SFM)}

The BSRTC category 4 and the THY category 4 are similar. The smear may be suspicious for papillary carcinoma, medullary carcinoma, lymphoma or malignancy not otherwise specified. The aim of having a separate suspicious category apart from the malignant category is to preserve the very high positive predictive value of the malignant category without compromising the overall sensitivity of the procedure (6). A SFM diagnosis can be made when some of the diagnostic features are equivocal or absent, whereas a malignant diagnosis (BSRTC category 6) is made when all the criteria are present.

The management for this category is surgery. When confronted with this category clinicians can resort to alternate management options such as surgical lobectomy with intra-operative frozen section before doing total thyroidectomy. The usefulness of intraoperative frozen section has not been investigated. When compared with intraoperative frozen section, FNA has shown a comparable or higher sensitivity and positive predictive value for diagnosing papillary carcinoma of the thyroid $(28$, 29). The decision to undergo total thyroidectomy or lobectomy with or without frozen section will depend on the preference of the patient in consultation with the surgeon (6). Patients with large tumours over $4 \mathrm{~cm}$ in diameter can be considered for total thyroidectomy because of the increased risk of malignancy associated with tumours of this size (30). Ancillary tests may be useful for patients with a diagnosis of suspicious for medullary carcinoma. An elevated serum calcitonin and/or a repeat FNA that shows strong immunoreactivity for chromogranin, synaptophysisn and calcitonin can convert a category 5 diagnosis of medullary carcinoma to a category 6 or definite diagnosis of malignancy.

\section{BSRTC CATEGORY 6: MALIGNANT}

This is the least controversial of the diagnostic categories. This category is similar to THY 5 category. All the features indicative of a specific malignancy such as papillary or medullary carcinoma of the thyroid are present. The risk of malignancy is $97-100 \%$. Management of this category is total thyroidecomy.

\section{SUMMARY}

There are six diagnostic categories in the BSRTC. BSRTC differs from the five category THY system by the fact that each diagnostic category carries an implied cancer risk ranging from $0-3 \%$ for the "benign category" to nearly I00\% for the "malignant category". Each category in the BSRTC is linked to evidence based clinical management guidelines which makes it easier for surgeons to interpret reports in terms of further management. The management of BSRTC categories 1,2 and 3 is non-surgical whereas categories 4,5 and 6 is surgical. It must be emphasized however that interpretation and subsequent management of an individual patient will also depend on clinical and ultrasonographic features of the nodule. Many countries have adopted the BSRTC. It is time that Sri Lankan clinicians and pathologists had a joint discussion whether this system should be adopted in Sri Lanka as well.

\begin{tabular}{|l|l|}
\hline $\begin{array}{l}\text { Table I: Diagnostic categories of the } \\
\text { Bethesda system for reporting thyroid } \\
\text { Cytopathology (BSRTC) (6) }\end{array}$ \\
\hline I. & Nondiagnostic or Unsatisfactory \\
\hline 2. & Benign \\
\hline 3. & $\begin{array}{l}\text { Atypia of Undetermined Significance } \\
\text { or Follicular Lesion of Undetermined } \\
\text { Significance }\end{array}$ \\
\hline 4. & $\begin{array}{l}\text { Follicular Neoplasm or Suspicious for } \\
\text { Follicular neoplasm }\end{array}$ \\
\hline 5. & Suspicious for malignancy \\
\hline 6. & Malignant \\
\hline
\end{tabular}




\begin{tabular}{|l|l|l|}
\hline \multicolumn{3}{|l|}{$\begin{array}{l}\text { Table 2: Implied risk of malignancy for } \\
\text { Bethesda diagnostic categories and } \\
\text { recommended clinical management (6) }\end{array}$} \\
\hline $\begin{array}{l}\text { Diagnostic } \\
\text { category }\end{array}$ & $\begin{array}{l}\text { Risk of } \\
\text { malignancy }\end{array}$ & Usual management \\
\hline Category I & & $\begin{array}{l}\text { Repeat FNA with } \\
\text { ultrasound }\end{array}$ \\
\hline Category 2 & $0-3 \%$ & Clinical follow up \\
\hline Category 3 & $5-15 \%$ & Repeat FNA \\
\hline Category 4 & $15-30 \%$ & Surgical lobectomy \\
\hline Category 5 & $60-75 \%$ & $\begin{array}{l}\text { Surgical lobectomy } \\
\text { or near-total } \\
\text { thyroidectomy }\end{array}$ \\
\hline Category 6 & $97-100 \%$ & $\begin{array}{l}\text { Near-total } \\
\text { thyroidectomy }\end{array}$ \\
\hline
\end{tabular}

\begin{tabular}{|c|c|}
\hline \multicolumn{2}{|c|}{$\begin{array}{l}\text { Table 3:The THY system for reporting } \\
\text { thyroid FNA based on Guidance on the } \\
\text { reporting of thyroid FNA by the Royal } \\
\text { College of Pathologists }\end{array}$} \\
\hline Thy I category: & $\begin{array}{l}\text { Non-diagnostic for cytology } \\
\text { diagnosis }\end{array}$ \\
\hline Thy 2 category: & Non-neoplastic \\
\hline Thy 3 category: & Neoplasm possible \\
\hline Thy 4 category: & Suspicious for malignancy \\
\hline Thy 5 category: & Malignant \\
\hline
\end{tabular}

\section{REFERENCES:}

I. Piromali D, Martelli G, Del Prato I, Collins P, Pilotti S. The role of fine needle aspiration in the diagnosis of thyroid nodules. Analysis of 795 consecutive cases. Journal of Surgical Oncology 1992; 50: 247-50.

2. De Silva MVC. Diagnosis of thyroid disease-the role of the pathologist. Ceylon Medical Journal 2007; 52: 4-6

3. Yoder B], Redman R, Massoll NA.Validation of a fivetier cytodiagnostic system for thyroid fine needle aspiration biopsies using cytohistologic correlation. Thyroid. 2006; 16:78I-86.

4. Redman R, Yoder BJ, Massoll N. Perceptions of diagnostic terminology and cytopathologic reporting of fine-needle aspiration biopsies of thyroid nodules: a survey of clinicians and pathologists. Thyroid. 2006; 16: 1003-1008.

5. Guidance on the reporting of thyroid cytology specimens. The Royal College of pathologists. (Accessed at http:// www.rcpath.org/Resources/RCPath/ Migrated\%20Resources/Documents/G/g089 guidanceonthereportingofthyroidcytologyfinal.pdf.

6. Ali SZ, Cibbas ES.The Bethesda system for reporting thyroid cytopathology. Definitions, criteria and Explanatory notes. Springer. New York. 2010. I-3.

7. Baloch ZW, Cibbas ES, Clark DP et al.The National Cancer Institute Thyroid fine needle aspiration state of the science conference: a summation. Cytojournal 2008; 5:6

8. Baloch ZW, LiVolsiVA,Asa SL Rosai J et al. Diagnostic terminology and morphologic criteria for cytologic diagnosis of thyroid lesions:a synopsis of the National Cancer Institute Thyroid fine needle aspiration state of the science conference:Diagnostic Cytopathology 2008: 36: 425-37.

9. Kinni SR, Smith-PurslowMJ. Adequacy, reporting system and cytopreparatory technique. In: Kini SR ed. Guides to clinical aspiration biopsy. Thyroid. 2nd edition. New York. Igashu Shoin Medical publishers 1996: I3-28

10. Deshpande V, kapila K, sai KS, Verma K. follicular neoplasms of the thyroid. Decision traee approach using morphologic and morphometric parameters. Acta Cytologica 1997;41:369-76.

II. Layfield LJ, Abrahams J, Cochand-Priollet B et al. Post thyroid FNA testing and treatment options. A synopsis of the National Cancer Institute Thyroid fine needle aspiration state of the science conference: Diagnostic Cytopathology 2008: 36: 442-48.

12. Alaxander EK, Heering JP, Benson CB et al. Assessment of non-diagnostic ultrasound guided fine needle aspirations of thyroid nodules. Jounal of clinical Endocrinology and Metabolism. 2002; 87:4924-27.

13. MacDonald L, Yazdi HM. Nondiagnostic fine needle aspiration of the thyroid gland: a diagnostic dilemma. Acta Cytologica 1996: 40:423-28.

14. Oertel YC, Oertel JE. Diagnosis of benign thyroid lesions: fine needle aspiration and histopathologic correlation. Annals of Diagnostic Pathology. 1998; 2: 250-63.

15. Suen KC. How does one separate celluar follicular lesions of the thyroid by fine needle aspiration biopsy? Diagnostic Cytopathology 1988; 4: 78-8I.

16. Kumarasinghe MP, De Silva S. pitfalls in cytological diagnosis of autoimmine thyroiditis. Pathology 1999; 3I: I-7

17. MacDonald L, Yazdi HM. Fine needle aspiration biopsy of Hashimoto's thyroiditis. Sources of diagnostic error.Acta Cytologica 1999; 43: 400-406.

18. Cooper DS, Doherty GM, Haugen BR et al. Management guidelines for patients with thyroid nodules and differentiated thyroid cancer. Thyroid 2006; 16: 109-42. 
19. Gharib H, GoellnerJR. Fine needle aspiration of the thyroid an appraisal. Annals of internal Medicine 1993; I 1 8: 282-89.

20. Yeh MW, Demrican O, Ituarte P, Clark OH. False negative fine needle aspiration cytology results delay treatment and adversely affect outcome of patients with thyroid carcinoma. Thyroid 2004; I4: 207-2 I5.

21. Tee YY. Lowe AJ, Brand CA Judson RT. Fine needle aspiration may miss a third of all malignancy in palpable thyroid nodules: a comprehensive literature review.Annals of Surgery 2007; 246: 7I4-720.

22. Yassa L, Cibas ES, Benson CB et al. Long term assessment of a multidisciplinary approach to thyroid nodule diagnostic evaluation. Cancer 2007; III:508-16.

23. Nayar R. Ivanovic M. The indeterminate thyroid FNA: Experience from an academic center using terminology similar to that proposed in the 2007 $\mathrm{NCl}$ Thyroid Fine Needle Aspiration State of the Science Conference. Cancer Cytopathology 2009; I 17: 195-202.

24. Stelow EB,Bardales RH,Crary GS et al.Interobserver variability in thyroid fine needle aspiration interpretationof lesions showing predominantly colloid and follicular groups. American Journal of Clinical Pathology 2005; 1 24:239-44

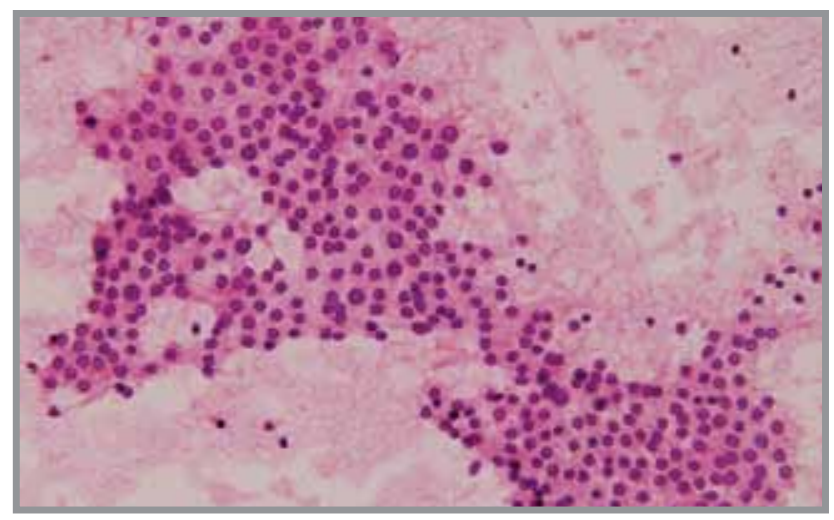

BSRTC category 2. Benign smear with uniform cells forming a honeycomb sheet

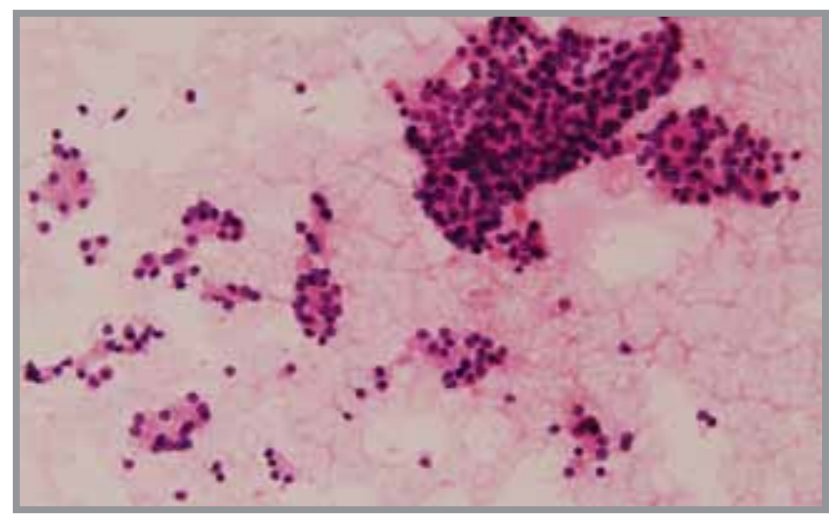

BSRTC category 4: Follicular neoplasm or suspicious for follicular neoplasm. Crowded sheet with several microfollicular structures
25. Clary KM, Condel JL, Liu $Y$ et al. Interobserver variability in the fine needle aspiration biopsy diagnosis of follicular lesions of the thyroid gland. Acta Cytologica 2005: 49: 378-82.

26. Yang J, Schnadig V, Logrono $R$ et al. Fine needle aspiration of thyroid nodules:a study of 4703 patients with histologic and clinical correlation. Cancer 2007: III:306-I5.

27. Deveci MS, Deveci G, LiVolsi VA et al. Fine needle aspiration of follicular lesions of the thyroid Diagnosis and follow up. Cytojournal 2006; 3:9

28. Hamburger JL, Husain M. Contribution of intraoperative pathology evaluation to surgical management of thyroid nodules. Endocrinol Metab Clin North Am 1990; 19:509-22.

29. Lee Ti, Yang HJ, Lin SY et al. The accuracy of fine needle aspiration biopsy and frozen section in patients with thyroid cancer.Thyroid. 2002; 12:61926.

30. Cooper DS, Doherty GM, Haugen BR et al. Managemnet guidelines for patients with thyroid nodules and differentiated thyroid cancer. Thyroid 2006; 16: 109-142

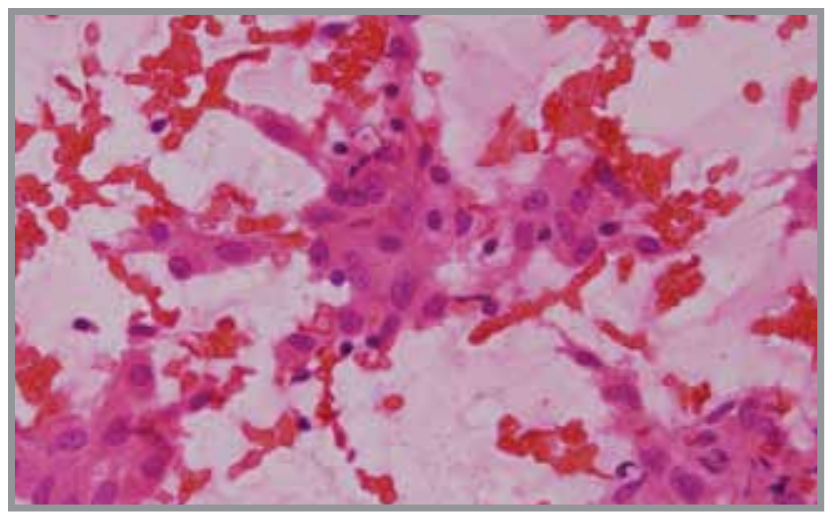

BSRTC category 3.Atypia of undetermined significance

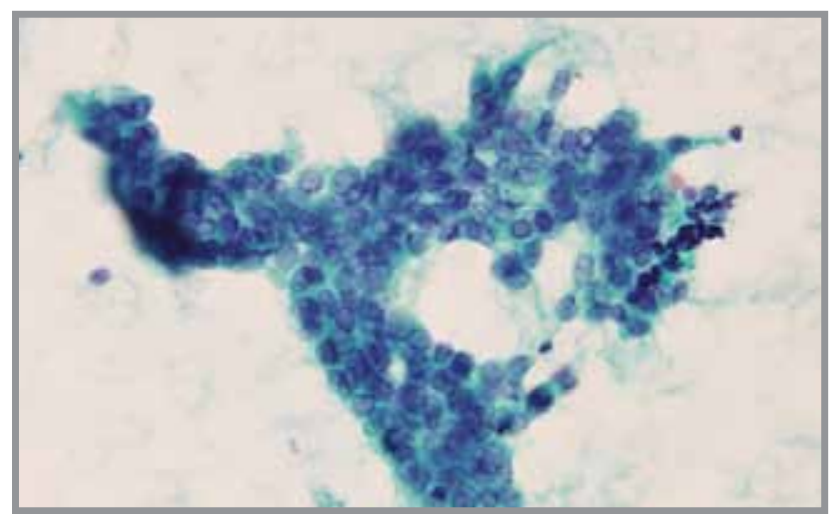

BSRTC category 6. Papillary carcinoma. Nuclear clearing and grooves in a papillaroid fragment. More features of papillary carcinoma were present in other fields 